\title{
Fabrication of Nitrogen-Doped Carbon Nanofiber Networks for Oxygen Reduction Reaction
}

\author{
Shiming Meng, Mei Yu* , Jianhua Liu, Songmei Li \\ School of Materials Science and Engineering, Beihang University, Beijing 100191, China \\ *E-mail: yumei@buaa.edu.cn \\ doi: $10.20964 / 2017.06 .12$
}

Received: 3 March 2017 / Accepted: 29 March 2017 / Published: 12 May 2017

\begin{abstract}
In this work, nitrogen-doped carbon nanofiber networks (NCFWs) were fabricated by a simple method of paralyzing polypyrrole nanofiber networks (PPy NFWs) precursor. Scanning electron microscopy (SEM), Transmission electron microscopy (TEM), X-ray diffraction (XRD) and Fourier transform infrared spectroscopy (FTIR) were employed to investigate the microstructure and composition of the as-prepared sample. Then the nitrogen-doped carbon nanofiber networks was further evaluated for its performance on Oxygen reduction reaction (ORR) with Cyclic voltammograms (CVs) and Linear sweep voltammograms (LSVs). The results showed that the fabricated NCFWs exhibited more remarkable catalytic performance compared with nitrogen-doped carbon nanoparticles (NFPs). Thus this material could be used as a better candidate in the field of fuel cells and metal-air batteries. The pyrolysis and structure of the NCFWs has obvious influence on their enhenced ORR properties.
\end{abstract}

Keywords: Oxygen reduction reaction; polypyrrole; networks; carbon; paralysis

\section{FULL TEXT}

(C) 2017 The Authors. Published by ESG (www.electrochemsci.org). This article is an open access article distributed under the terms and conditions of the Creative Commons Attribution license (http://creativecommons.org/licenses/by/4.0/). 